\title{
The mitochondrial and endoplasmic reticulum pathways involved in the apoptosis of bursa of Fabricius cells in broilers exposed to dietary aflatoxin $B_{1}$
}

\author{
Shibin Yuan ${ }^{1,2, *}$, Bangyuan $\mathrm{Wu}^{1,2, *}$, Zhengqiang $\mathrm{Yu}^{3, *}$, Jing Fang ${ }^{3}$, $\mathrm{Na}$ Liang $^{3}$, \\ Mingqiang Zhou ${ }^{1,2}$, Cheng Huang ${ }^{1,2}$, Xi Peng ${ }^{1,2}$ \\ ${ }^{1}$ Department of Wild Animal Disease, College of Life Science, China West Normal University, Nanchong 637009, Sichuan, \\ The People's Republic of China \\ ${ }^{2}$ Key Laboratory of Southwest China Wildlife Resources Conservation (China West Normal University), Ministry of Education, \\ Nanchong 637009, Sichuan, The People's Republic of China \\ ${ }^{3}$ Department of Animal Pathlogy, College of Veterinary Medicine, Sichuan Agricultural University, Ya'an 625014, Sichuan, The \\ People's Republic of China \\ *These authors have contributed equally to this work \\ Correspondence to: Xi Peng, email: pengxi197313@163.com
}

Keywords: aflatoxin $B_{1}$, bursa of Fabricius, apoptosis, oxidative stress, broiler

Received: May 27, 2016

Accepted: July 28, 2016

Published: August 17, 2016

\section{ABSTRACT}

Aflatoxin $B_{1}\left(A F B_{1}\right)$, a toxic metabolite produced by some fungi, exerts wellknown hepatocarcinogenic and immunosuppressive effects, the latter can increase the apoptotic immune cells in vitro. However, it is largely unknown that which signaling pathways contribute to excessive apoptosis of immune cells which induced by AFB $_{1}$. In this study, we investigated the roles of the mitochondria, endoplasmic reticulum (ER) and death receptor activated apoptotic pathways in the bursal of Fabricius (BF) cells in the broilers exposed to $A F B_{1}$ diet. We found that (1) $A F B_{1}$ diet induced morphological changes in the BF. (2) FCM and TUNEL methods showed that excessive

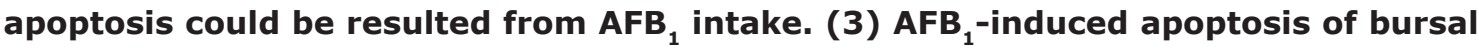
cells involved mitochondrial pathway (increase of Bax, Bak, cytC, caspase-9, Apaf-1, caspase-3 and decrease of Bcl-2 and Bcl-xL) and ER pathway (increase of Grp78/Bip, Grp94 and CaM). (4) Oxidative stress was confirmed in the BF of chicken fed on AFB diet. Overall, this work is the first to demonstrate that the activation of mitochondria and ER apoptosis pathways can lead to excessive apoptosis in BF cells, and oxidative stress is a crucial driver during AFB $_{1}$ exposure.

\section{INTRODUCTION}

Aflatoxins (AFs), kind of widespread contaminants of foods and feeds, are toxic metabolites produced by Aspergillus flavus and A. parasiticus. Among the four major types of AFs (Aflatoxin $\mathrm{B}_{1}, \mathrm{~B}_{2}, \mathrm{G}_{1}, \mathrm{G}_{2}$ ), Aflatoxin $\mathrm{B}_{1}\left(\mathrm{AFB}_{1}\right.$ ) is the most potent carcinogen, due to its demonstrated toxic and carcinogenic effects in livestock, poultry and its acute toxicological or chronic hepatocarcinogenic effects in humans $[1,2]$. To exert these toxic effects, $\mathrm{AFB}_{1}$ requires to convert to $\mathrm{AFB}_{1}-8,9$-exo-epoxide (AFBO) [3]. In livestock and laboratory animals, negative effects associated with $\mathrm{AFB}_{1}$ exposure include growth retardation and poor feed conversion, increased mortality and leg problems [4-6]. In poultry, decreased reproductive ability, liver and kidney injuries, as well as immunosuppression were observed [710]. Moreover, $\mathrm{AFB}_{1}$ contaminated rations resulted in the presence of $\mathrm{AFB}_{1}$ residues in their edible tissues like liver, muscles and eggs [11, 12], which can potentially create some human health issues [13].

Secondary to the effects on liver, the immunosuppressive nature of $\mathrm{AFB}_{1}$ is the best documented area of its toxicity [14], which is related to the increase of disease susceptibility and mortality. Chicken is sensitive to $\mathrm{AFB}_{1}$. Low dosages of $\mathrm{AFB}_{1}$ may induce obvious immunosuppression, including the decrease of relative weight of immune organs, T-cell subsets, cytokines, antibody titers, complement activity, and pathologic injury of lymphoid tissues [15-18]. Several studies showed that AFB could induce lesions of immune organs in poultry $[19,20]$, 
and it was also suggested that $\mathrm{AFB}_{1}$ treatment could induce oxidative stress, cell cycle arrest, excessive apoptosis, and mitochondria injury in lymphoid tissues of chickens in our previous researches [21-23]. These findings indicated that the injuries of immune organs might play critical roles in immunosuppression induced by $\mathrm{AFB}_{1}$ administration in chickens, but its mechanisms need to be further clarified.

Apoptosis is a process of programmed cell death that serves as a major mechanism for the precise regulation of cell numbers, and as a defense mechanism to remove unwanted and potentially dangerous cells [24]. It has been reported that the oxidative stress and apoptosis might play key roles in $\mathrm{AFB}_{1}$ induced immunotoxicity [22]. Our previous study demonstrated that $\mathrm{AFB}_{1}$ treatment caused alteration of $\mathrm{Bax}, \mathrm{Bcl}-2$, and caspase- 3 expressions, which involved in apoptosis via mitochondrial pathway in broiler's thymus and bursa of Fabricius (BF) [25, 26]. As we know that the mitochondria, death receptor, and endoplasmic reticulum (ER) activated apoptotic pathways are the three key pathways in apoptosis [27]. However, the exact mechanism of $\mathrm{AFB}_{1}$ induced $\mathrm{BF}$ injury has not been elucidated, and the signaling pathways of $\mathrm{AFB}_{1}$ induced $\mathrm{BF}$ apoptosis have not been investigated. The current study aimed to examine which apoptotic pathways maybe involved in this apoptotic procedure by using a broiler model.

In this study, we demonstrated that mitochondria and ER activated apoptosis pathways could be triggered in the excessive apoptosis of BF cells in the chickens fed with $\mathrm{AFB}_{1}$ diet. The increased mRNA expressions of p53, Bax, Bak, cytC, caspase-9, Apaf-1, caspase-3 and decreased expressions of $\mathrm{Bcl}-2$ and $\mathrm{Bcl}-\mathrm{xL}$ were related to the activation of mitochondria pathway. And the increased expressions of Grp78/Bip, Grp94 and CaM mean that the ER apoptosis pathway was involved. Decreased antioxidant capacity suggested that oxidative stress might be an important mechanism of excessive apoptosis of BF cells in this study. Our research also found that the mitochondria and death receptor pathways were involved in $\mathrm{AFB}_{1}$-induced apoptosis of thymocytes in chicken [28], which was different from BF cells. Its possible reasons were analyzed in this paper too.

\section{RESULTS}

\section{Relative weight of bursa of Fabricius}

Compared with those of the control group, the relative weight of BF was significantly decreased $(\mathrm{p}<0.01)$ at 21 days of age. The results were shown in Figure $1 \mathrm{~A}$.

\section{Histopathological and ultrastructural analysis}

Compared with the control group (Figure 1B), there were more vacuoles and debris in the lymphoid follicle of $\mathrm{BF}$ in the $\mathrm{AFB}_{1}$ group at 7 and 14 days of age, and increased debris were almost in the vacuoles. More vacuoles, more debris and decreased lymphocytes were observed in the lymphoid follicle of BF at 21 days of age (Figure 1C, 1D). Incidence of major histological lesions of BF is shown in Table 1.

In the $\mathrm{BF}$ of broilers in the $\mathrm{AFB}_{1}$ group, there were some occasional necrotic cells with dilation of perinuclear cisternae, rarefaction of euchromatin and margination of heterochromatin with loss of details. Increased apoptotic cells were characterized as condensed chromatin with petal shape or irregular shape. At the same time, expansive mitochondria with fewer cristae and dilated endoplasmic reticulum are observed in the suspected plasmocytes in the $\mathrm{BF}$. The results are shown in Figure 1F, $1 \mathrm{G}$.

\section{Apoptotic BF cells analysis by TUNEL assay and flow cytometry method}

The apoptotic BF cells were stained brown (Figure $2 \mathrm{~A}$ and $2 \mathrm{~B}$ ) or with green fluorescence (Figure 2C and 2D). The results showed that these apoptotic cells were mostly observed in the medulla of lymphoid follicle. The percentages of apoptotic BF cells in the $\mathrm{AFB}_{1}$ group were significantly increased when compared with those of the control group at 7, 14 and 21 days of age $(\mathrm{P}<0.01)$. The statistical results are shown in Figure $2 \mathrm{G}$.

Annexin-V-FITC was used to determine the percentage of cells undergoing apoptosis. Apoptotic cells were examined by counting the total percentage of early apoptotic cells (Annexin-V positive and PI negative) and late apoptotic cells (both Annexin-V and PI positive). The results of FCM analysis revealed similar trend as TUNEL. The percentages of apoptotic BF cells in the $\mathrm{AFB}_{1}$ group (Figure 2F, 2H) were significantly higher $(\mathrm{p}<0.01)$ than those in the control group at 7,14 and 21 days of age (Figure 2E, 2H), and the statistical results are shown in Figure $2 \mathrm{H}$.

\section{Changes of $\Delta \psi \mathrm{m}$}

Apoptosis is frequently associated with depolarization of mitochondrial membrane potential $\left(\Delta \psi_{\mathrm{m}}\right)$, which present as reduced JC-1 fluorescence by flow cytometer. That is, the apoptotic population frequently presents lower red fluorescence signal intensity. The results showed that the number of cells with lower red fluorescence in the $\mathrm{AFB}_{1}$ group was significantly higher than that in the control group $(\mathrm{p}<0.01)$ at 7,14 and 21 days of age. The results are shown in Figure 3.

\section{qRT-PCR analysis of relative expressions of apoptosis- and antioxidative-related genes}

At 7, 14 and 21 days of age, the increased $(\mathrm{p}<0.05$ or $\mathrm{p}<0.01$ ) mRNA expressions of Bax, apaf-1, Grp78/Bip, Grp94, calmodulin (CaM) and p53, decreased $(\mathrm{p}<0.05$ or 
$\mathrm{p}<0.01)$ expressions of $\mathrm{Bcl}-\mathrm{xL}$ and $\mathrm{Bcl}-2$ were observed in the $\mathrm{BF}$ of the $\mathrm{AFB}_{1}$-fed broilers. At 14 and 21 days of age, the mRNA expressions of Bak-1, cytC, casp-9 and casp3 in the BF of the $\mathrm{AFB}_{1}$ group were increased $(\mathrm{p}<0.05$ or $\mathrm{p}<0.01)$ and akt1 was decreased significantly $(\mathrm{p}<0.05$ or $\mathrm{p}<0.01$ ) when compared with those of the control group. What's more, the mRNA content of FasL, casp-10 was decreased at 7 days, and the AIF mRNA level was increased at 14 days of age in the $\mathrm{AFB}_{1}$ group (Figure 4).

Comparing with those of the control group, the mRNA expressions of CuZn-SOD, Mn-SOD and CAT were significantly decreased $(p<0.05$ or $p<0.01)$ in the $\mathrm{AFB}_{1}$ group at 7, 14 and 21 days of age. What's more, the mRNA contents of GSH-Px and GR were obviously lower $(p<0.05$ or $p<0.01)$ at 7 and 21 days of age than those in the control group (Figure 5).

\section{Antioxidation biochemistry analysis parameters}

At 14 and 21 days of age, the activities of CAT, GSH-Px, SOD, GR and T-AOC were significantly lower $(\mathrm{p}<0.01$ or $\mathrm{p}<0.05)$ than those in the control group.

$\mathbf{A}$
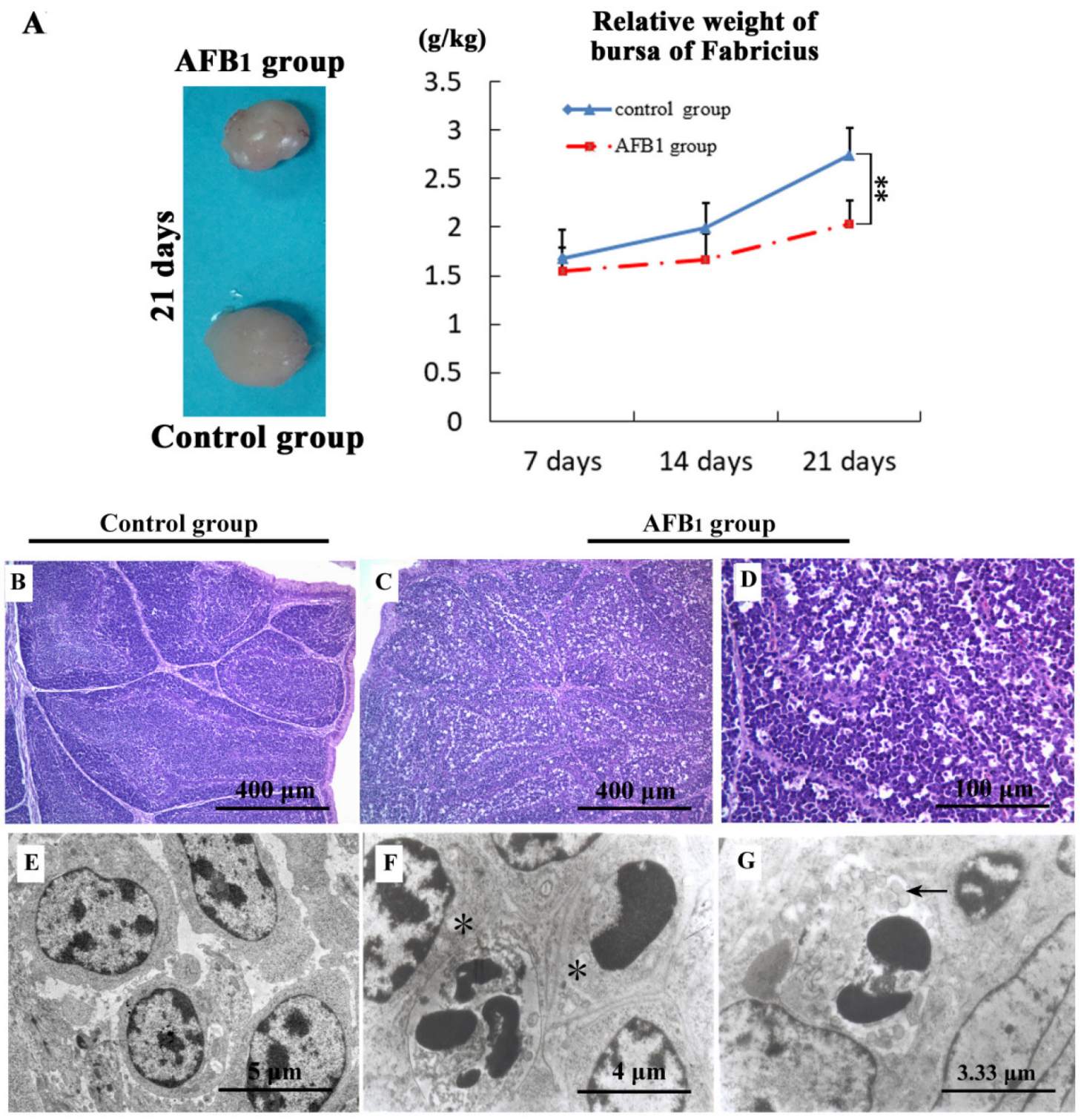

Figure 1: The suppress of aflatoxin B1 exposure on bursa of Fabricius relative weight, histopathology and ultrastructural pathology. A. The broilers from control and $\mathrm{AFB}_{1}$ group, relative weight of $\mathrm{BF}$. Histological assessment of $\mathrm{H} \& \mathrm{E}$-stained $\mathrm{BF}$ tissues from 21-day-old broilers exposed to $\mathrm{AFB}_{1}$ diet $\mathbf{C}, \mathbf{D}$. and control diet $\mathbf{B}$. more vacuoles and debris in the lymphoid follicle. Ultrastructural assessment of uranyl acetate and lead citrate stained bursa of Fabricius sections from the control $\mathbf{E}$. and $\mathrm{AFB}_{1}$ group F, G. More apoptotic cells, vacuolated mitochondria with degenerated cristae $\left(^{*}\right)$, and expanded ER with high electron density $(\leftarrow)$ in lymphocytes of BF. 
Table 1: Incidence of major histological lesions of bursa of Fabricius

\begin{tabular}{lccc}
\hline Pathological Lesions & Time & Control group & AFB $_{1}$ group \\
\hline \multirow{3}{*}{ Vacuoles increased } & 7 days & $0 / 6$ & $3 / 6$ \\
& 14 days & $0 / 6$ & $4 / 6$ \\
Nuclear fragmentation & 21 days & $0 / 6$ & $6 / 6$ \\
increased & 7 days & $0 / 6$ & $1 / 6$ \\
& 14 days & $0 / 6$ & $4 / 6$ \\
\hline
\end{tabular}

Incidence of lesions in the $\mathrm{BF}$ among animals from different experimental groups $(\mathrm{n}=6)$.
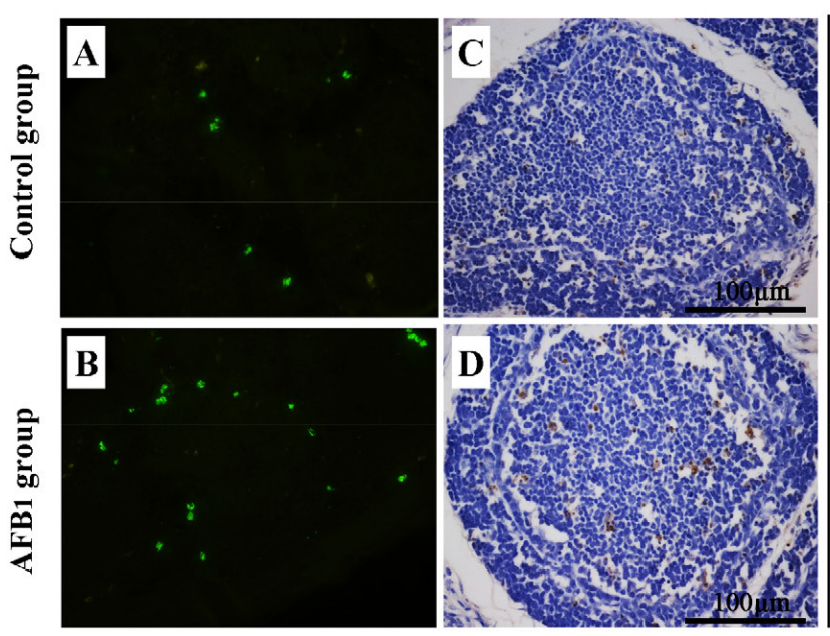
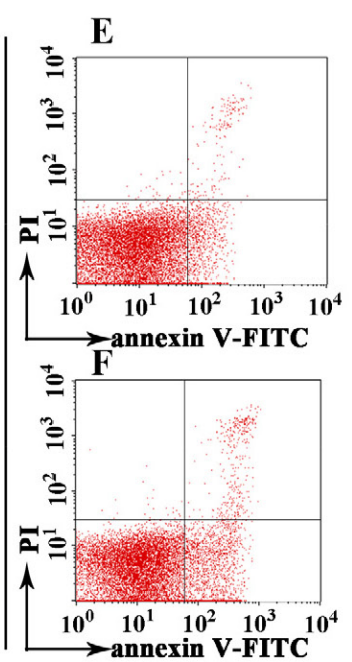

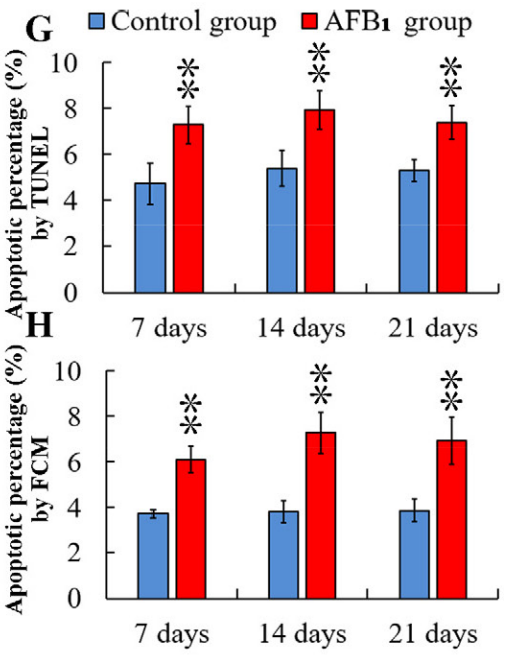

Figure 2: Percentage of apoptotic bursal lymphocytes from the broilers exposed to the control and AFB diets. TUNEL $_{1}$ stained slices of the BF from 21-day-old broilers in the control $\mathbf{A}$. and $\mathbf{C}$. and $\mathrm{AFB}_{1}$ group $\mathbf{B}$. and $\mathbf{D}$. The nuclei of apoptotic cells were with green fluorescence (stained with FITC fluorescein-dUTP), or brown (stained with diaminobenzidine). Image $\mathbf{E}$. and $\mathbf{F}$. are representatives of the apoptosis by FCM. Bar graph G. and $\mathbf{H}$. indicate the mean with standard deviation, and are representatives of apoptosis rate by TUNEL and $\operatorname{FCM}(* \mathrm{p}<0.05, * * \mathrm{p}<0.01$ vs control), six birds per group.
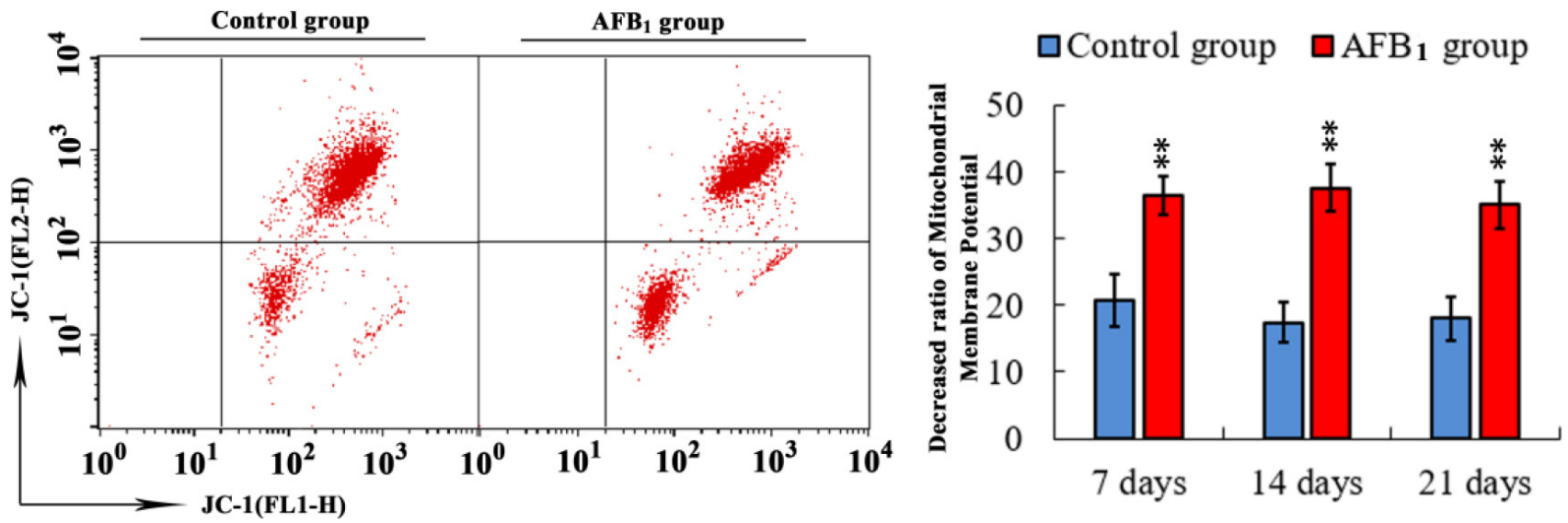

Figure 3: Determining mitochondrial membrane potential in bursa of Fabricius from the broilers exposed to the control and AFB diets. Assessment of mitochondrial membrane potential of BF cells with JC-1 staining by flow cytometry method. Bar graph indicates the mean with standard deviation, and are representatives of the percentage of bursal cells with lowered red fluorescence $\left({ }^{*} \mathrm{p}<0.05,{ }^{* *} \mathrm{p}<0.01\right.$ vs control), six birds per group. 
Comparing to the control group, the decreased $(\mathrm{p}<0.05$ or $\mathrm{p}<001)$ contents of GSH and increased $(\mathrm{p}<0.05$ or $\mathrm{p}<0.01)$ contents of MDA were observed in the $\mathrm{AFB}_{1}$ group at 7 , 14 and 21 days of age. The results are shown in Figure 5.

\section{DISCUSSION}

The BF of birds is a specific central immune organ for the proliferation and diversification of B cells, so it is correlated to the humoral immune function. In the present study, dietary $\mathrm{AFB}_{1}$ was found to induce the decrease of relative weight, obvious histopathological injury and ultrastructural impairment in the BF of chicken. Previous studies showed that increased vacuoles, nuclear debris and decreased lymphocytes could be a stable histological phenotype of lymphoid tissues [21, 29-31], and increased apoptotic cells and impaired membrane system were observed by ultrastructural examination in $\mathrm{AFB}_{1}$-treated broilers [20]. The histopathological and ultrastructural lesions of BF may be one of the main factors of humoral immunosuppression induced by $\mathrm{AFB}_{1}$. In this study, dietary $\mathrm{AFB}_{1}$ could cause excessive apoptosis of BF cells at early-stage by FCM method and at late-stage by TUNEL assay. Our results were agreed with previous viewpoint [32-34] that the reduced immune function could result from excessive apoptosis of immune cells.

As we know, the mitochondria, ER and death receptor activated apoptotic pathways are the three key pathways in apoptosis [27]. We were therefore interested in discovering which apoptotic pathways play major roles in excessive apoptosis of BF in this study.

The depolarization of $\Delta \psi_{m}$ was considered to be an early case in mitochondria activated apoptotic pathway [35]. The percentage of BF cells with depolarized $\Delta \psi_{m}$ was increased, and the swelling of mitochondria was induced by $\mathrm{AFB}_{1}$ in our study. The mRNA expressions of Bax, Bak, cytC, caspase-9, Apaf-1, caspase-3 were increased and the mRNA expressions of Bcl-2 and Bcl-xL were decreased in the BF, which were correlated to activating of
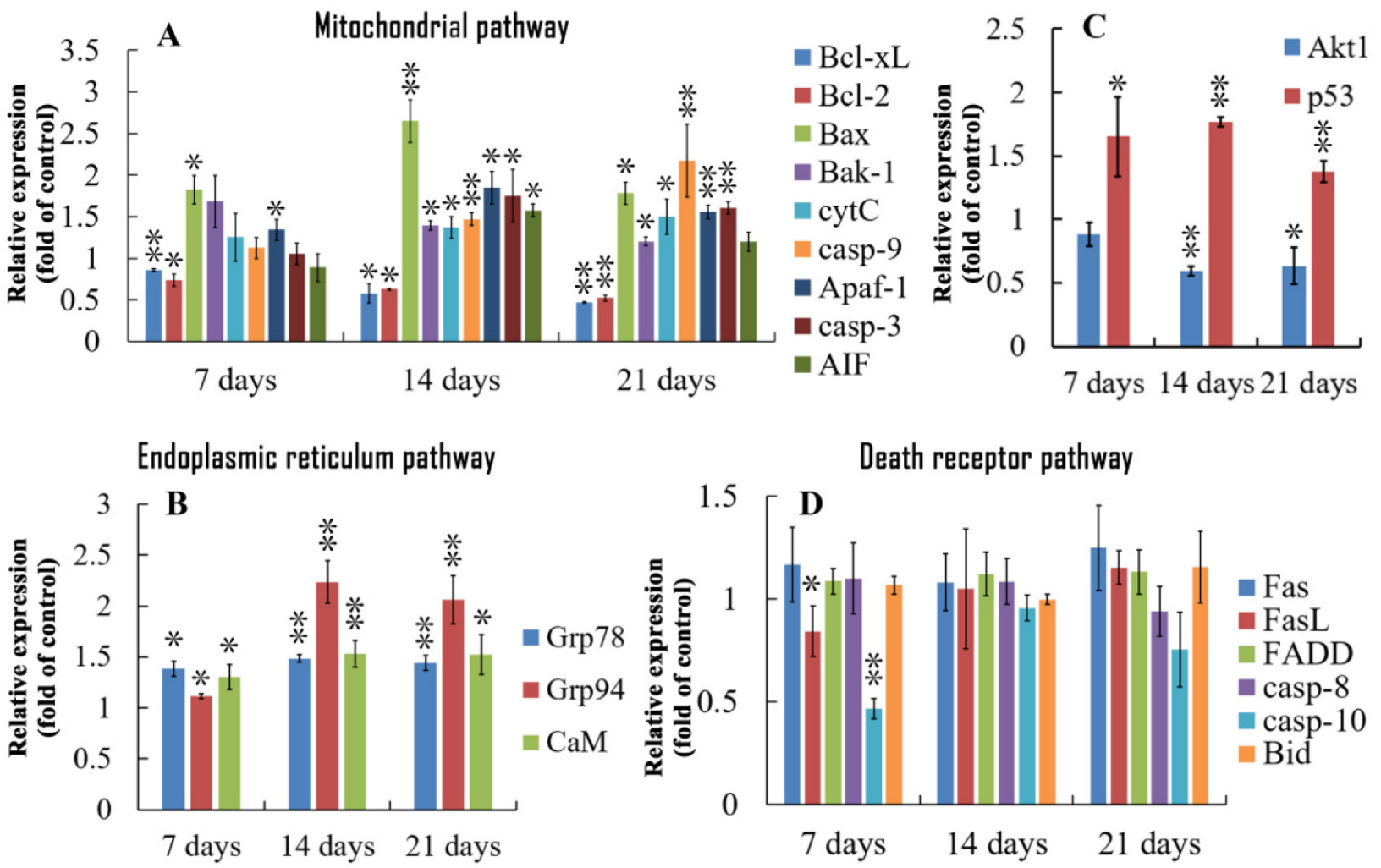

Figure 4: Relative expression of genes regulating apoptosis in bursa of Fabricius from the broilers exposed to the control and $\mathbf{A F B}_{1}$ diets. A. In the mitochondrial pathway, the mRNA expressions of Bcl-xL, Bcl-2, Bax, Bak-1, cytC, casp-9, Apaf-1 and casp-3 in the bursa cells of the $\mathrm{AFB}_{1}$-fed broilers are expressed as fold change relative to the control-fed broilers. B. In the endoplasmic reticulum pathway, the mRNA levels of Grp78/Bip, Grp94 and CaM in the bursal cells of the $\mathrm{AFB}_{1}$-fed broilers are expressed as fold change relative to the control-fed broilers. C. The mRNA expressions of p53 and Akt1 in the bursal cells of the AFB-fed broilers are expressed as fold change relative to the control-fed broilers. D. In the death receptor pathway, the mRNA expression of Fas, FasL, FADD, casp-8, casp-10 and Bid have no obvious changes compared to the control-fed broilers. All data are expressed as the mean value with deviation. $* \mathrm{p}<0.05, * \mathrm{p}<0.01$ vs control, $\mathrm{n}=6$ for each group. 
the mitochondrial pathway. The results were in accordance with the changes of corresponding proteins (Bax, Bcl-2 and caspase-3) [26]. Our data suggested that the excessive apoptosis of BF cells may result from the activation of mitochondria activated caspase-bind signaling pathway. Based on the changes of these genes and previous opinions $[36,37]$, a series of events might occur in the procedure of mitochondria mediated apoptotic pathway: homodimerize of overexpressed Bax, increased permeabilization of mitochondrial outer membrane, release of cytC and ATP from mitochondria, formation of tetramer (composed of caspase-9, Apaf-1, cytC and dATP), autocatalytic activation of caspase- 9 and activation of effector caspases including caspase-3. However, in our present study, the relative expression of apoptosis-inducing factor (AIF) had no obvious change when compared with that of the control, suggesting that non-caspase-bind apoptotic pathway was not active in this experiment.

The ER apoptosis pathway is initiated by ER stress, which is due to a number of factors, including cytotoxicity and nutrient limitation, and often characterize as the accumulation of unfolded or misfolded proteins [38, 39]. In the current study, the ER was enlarged with high electron density materials in the suspected plasmocytes, suggesting that unfold protein could be accumulated in ER. The optimum protein folding is decided by several factors including $\mathrm{Ca}^{2+}$, ATP and an oxidizing environment [40]. In the present study, the increased mRNA expression
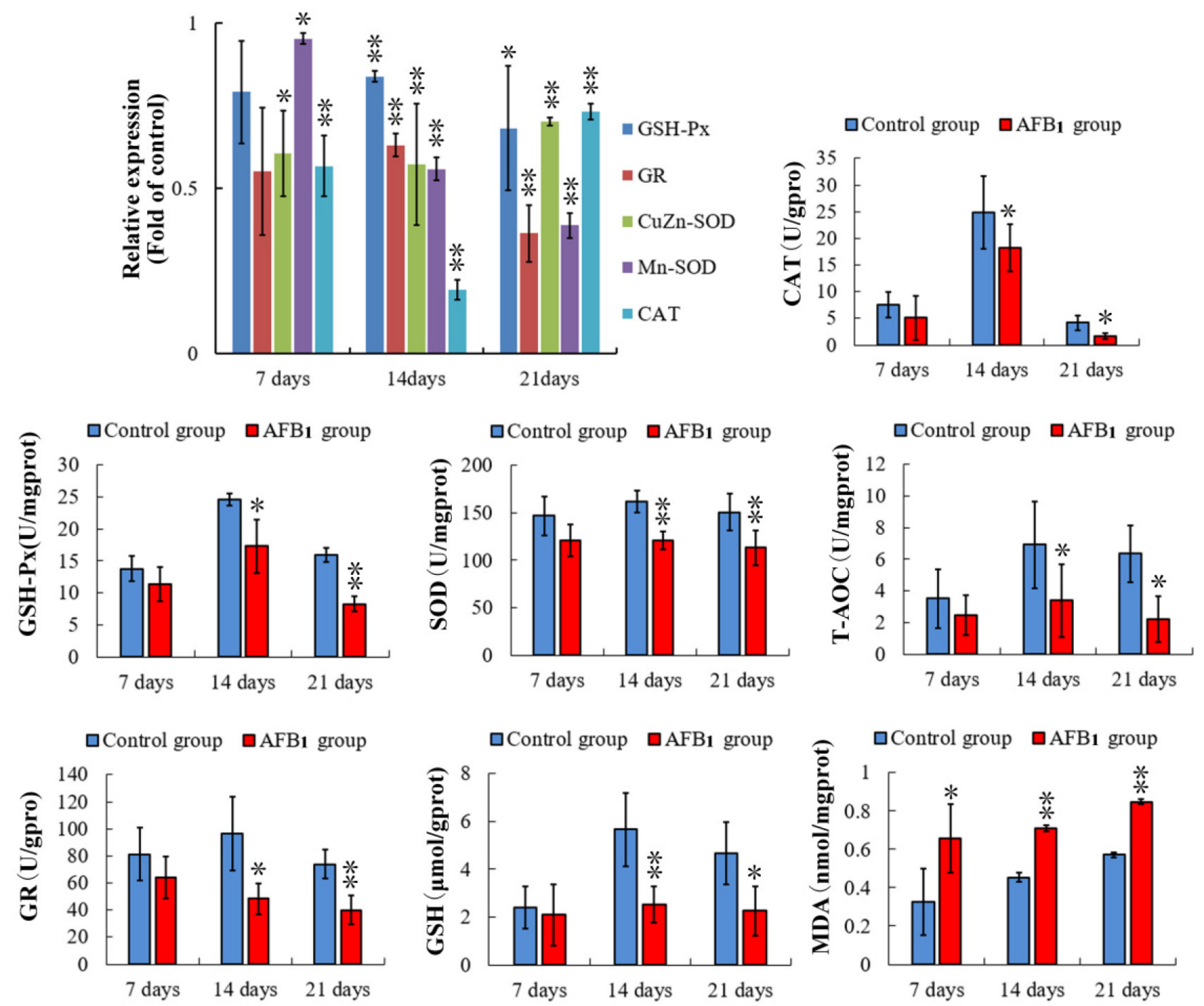

Figure 5: Assessment of the antioxidant function in bursa of Fabricius from the broilers exposed to the control and

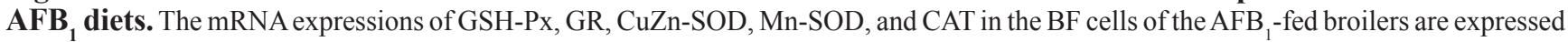
as fold change relative to the control-fed broilers. Others bar graph indicate the mean with standard deviation, and are representatives of the enzymatic activities of GSH-Px, GR, CuZn-SOD, Mn-SOD, CAT and T-AOC, and the contents of GSH and MDA $\left({ }^{*} \mathrm{p}<0.05, * * \mathrm{p}<0.01\right.$ vs control), six birds per group. 
of $\mathrm{CaM}$ which is important in regulating the concentration of $\mathrm{Ca}^{2+}$ [41], ATP deficiency induced by mitochondrial injury and oxidative stress might simultaneously result in unfolded protein response (UPR). The UPR could cause an imbalance of unfolded proteins and chaperones, lastly result in ER stress [42]. During ER stress, proapoptotic members of the Bcl-2 family are recruited to the ER surface, and activate caspase-12, which finally activates caspase-3 [43]. In this study, the increased expression of Grp78/Bip, Grp94 and calmodulin (CaM) showed that ER apoptosis pathway could be involved in the excessive apoptotic of bursal cells.

Furthermore, we investigated the relative mRNA expressions of genes correlated with death receptor apoptotic pathway. The results showed that the expressions of Fas, FasL, FADD, caspase-8, caspase-10 were no difference between the $\mathrm{AFB}_{1}$ group and the control group. The results evidenced that death receptor apoptotic pathway may not contribute to the excessive cell death of BF cells.
It is well accepted that oxidative stress is an apoptosis inducer $[44,45]$. An imbalance between ROS and the antioxidant may lead to the alteration of structure and function of proteins, lipids, and DNA, and then induce the damage of lipid membranes, cellular catalytic reactions, and finally cell apoptosis [46]. In the current study, the decreased activities of GSH-Px, SOD, CAT, GR, T-AOC, increased concentration of MDA, decreased content of GSH and decreased mRNA levels of antioxidant enzymes (GSH-Px, SOD, CAT and GR) were found in the BF from broilers fed with $\mathrm{AFB}_{1}$ diet. Our results suggested that oxidative stress may be a main mediator of excessive apoptosis of BF cells in this study.

Taken together, our results showed that dietary $\mathrm{AFB}_{1}$ exposure are able to induce excessive apoptosis of $\mathrm{BF}$ cells in chickens by triggering mitochondria and ER mediated apoptotic pathways (Figure 6), and oxidative stress may be the main factor being responsible for the activation of the two apoptosis pathways. Future studies will focus on a deeper understanding of the

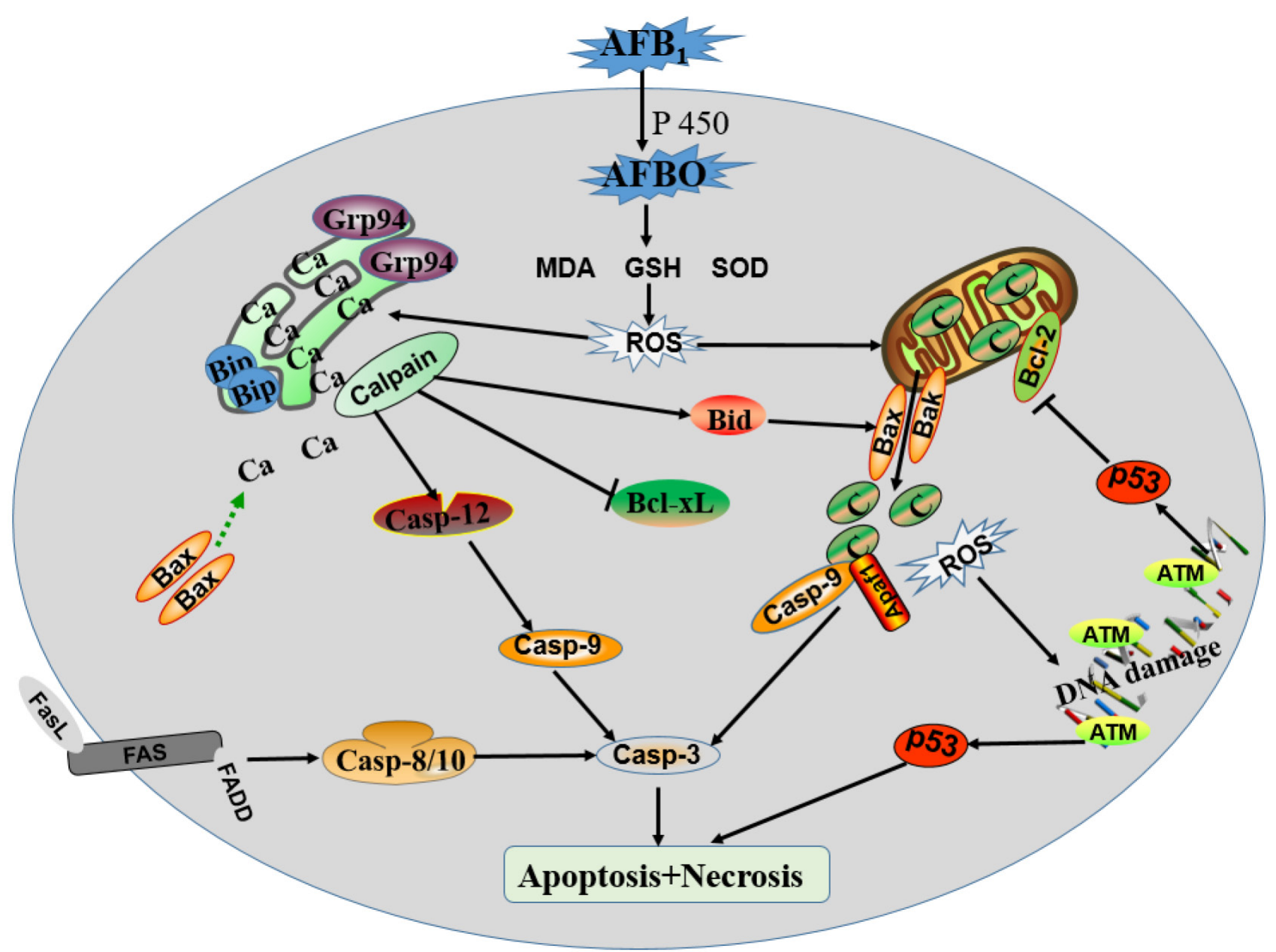

Figure 6: Schematic diagram of the proposed mechanisms of AFB induced apoptosis of BF cell. A proposed model of BF cells apoptosis by dietary $\mathrm{AFB}_{1}$ among mitochondria, endoplasmic reticulum and cell death receptor signaling pathways. ROS can induce mitochondria, endoplasmic reticulum stress, and DNA damage, and subsequently active the apoptosis signaling pathways. 
mechanisms of $\mathrm{AFB}_{1}$-induced immunosuppression. In the same research, we found an interesting phenomenon that different apoptosis-related signaling pathways were involved in the thymocytes and BF cell in chicken. Mitochondria and death receptor pathways were involved in thymocytes in chicken exposed to $\mathrm{AFB}_{1}[28]$, but Mitochondria and ER pathways in BF cells, suggesting that toxicological mechanisms were different in thymus and BF. So we can do further contrastive research to clarify this difference.

\section{MATERIALS AND METHODS}

\section{Chickens and diets}

One hundred and fifty-six one-day-old healthy Cobb-500 broilers were purchased from Chia Tai Group (Wenjiang, Sichuan, China), and were randomly divided into two equal groups of three replicates and 26 birds per replicate, namely control group $(0 \mathrm{mg} / \mathrm{kg}$ $\left.\mathrm{AFB}_{1}\right)$ and $\mathrm{AFB}_{1}$ group $\left(0.6 \mathrm{mg} / \mathrm{kg} \mathrm{AFB}_{1}\right)$. The basal diet, namely the control diet, was formulated according to National Research Council (NRC, 1994) [47] and Chinese Feeding Standard of Chicken (NY/T33-2004) recommendations. The $\mathrm{AFB}_{1}$-contaminated diet was made, referring to the method described by Kaoud [48]. Briefly, $27 \mathrm{mg} \mathrm{AFB}$ (A6636, Sigma-Aldrich, USA) was dissolved into $30 \mathrm{ml}$ methanol, and then the $30 \mathrm{ml}$ mixture was mixed into $45 \mathrm{~kg}$ corn-soybean basal diet to formulate the $\mathrm{AFB}_{1}$-contaminated diet. The equivalent methanol was mixed into corn-soybean basal diet to produce the control diet. Then the methanol of diets was evaporated at $98^{\circ} \mathrm{F}\left(37^{\circ} \mathrm{C}\right)$. The $\mathrm{AFB}_{1}$ concentrations were analyzed by HPLC with fluorescence detection (Waters Model 2475), and the $\mathrm{AFB}_{1}$ concentration were determined as $<0.001 \mathrm{mg} / \mathrm{kg}$ and $0.601 \mathrm{mg} / \mathrm{kg}$ respectively in the control diet and $\mathrm{AFB}_{1}$ diet. Broilers were housed in cages with electrically heated units and provided with water as well as aforementioned diet ad libitumfor 21 days. The animal protocols and all procedures of the experiment were performed in compliance with the laws and guidelines of Sichuan Agricultural University Animal Care and Use Committee (Approval No: 2012-024). The Ethics Committee for Animal Experiments (Institute of Animal Diseases \& Environmental Hazards of Sichuan Province, Chengdu, China) approved our experimental protocol.

\section{Relative weights of thymus and bursa of Fabricius}

At 7, 14, and 21 days of age, after the body weight was recorded, six birds in each group were euthanized and necropsied. Then the BF dissected from each bird and weighed after dissecting connective tissue around them.
Relative weight of BF was calculated by the following formula:

Relative weight=organ weight $(\mathrm{g}) /$ body weight $(\mathrm{kg})$

\section{Histopathological and ultrastructural examination}

Six broilers in each group were euthanized at 7, 14 and 21 days of age. The BF were fixed in $4 \%$ paraformaldehyde (PFA) and routinely processed in paraffin. Thin sections $(5 \mu \mathrm{m})$ of each tissue were sliced and mounted on glass. Slides were stained with hematoxylin and eosin Y. The histological structures of the tissues were observed and photographed with a digital camera (Nikon, eclipse 50i, Japan).

At the end of the trial, one chick per replicate in each group was euthanized and then immediately necropsied. Small pieces of BF tissues were rapidly fixed with 2.5 $\%$ glutaraldehyde and post-fixed in $2 \%$ Veronal acetatebuffered $\mathrm{OsO}_{4}$. After dehydration in graded alcohol, the tissues were embedded in Araldite. The blocks were sectioned in a microtome with a glass knife. Sections, 65$75 \mathrm{~nm}$ thick, were placed in uncoated copper grids. The sections were stained with uranyl acetate, and post-stained with $0.2 \%$ lead citrate. The subcellular structure of BF was examined with a Hitachi H-600 electron microscope (Japan).

\section{Annexin V-FITC/PI double staining assay}

The BF cells of six birds in each group were sampled to determine the apoptosis rate by flow cytometry method at 7,14 and 21 days of age. Bursal cell suspension was prepared by gently cutting with scissors, and filtered through a 300-mesh nylon screen. Then the cells were washed and suspended in phosphate buffer (PBS, PH: 7.2) at a concentration of $1 \times 10^{6}$ cells $/ \mathrm{mL}$. $100 \mu \mathrm{L}$ cell suspension was transferred to another centrifuge tube, and stained with $5 \mu \mathrm{L}$ of Annexin V-Fluorescein isothiocyanate (V-FITC) (BD Pharmingen, USA, 51-65874X) and $5 \mu \mathrm{L}$ of Propidium iodide (PI) (BD Pharmingen, USA, 51$66211 \mathrm{E}$ ) for $15 \mathrm{~min}$ at $25^{\circ} \mathrm{C}$ in the dark. Afterwards, 450 $\mu \mathrm{L}$ of $1 \times$ Annexin binding buffer (BD Pharmingen, USA, 51-66121E) was added to the mixture, and the percentages of apoptotic cells were assayed by FCM within 1 hour.

\section{TUNEL assay}

The DNA fragmentation indicative of apoptosis was examined using terminal deoxynucleotidyl transferasemediated dUTP nick end labeling method (TUNEL). TUNEL assay was performed using Insitu Cell Death Detection Kit (Cat. NO. 11684817910, Roche Molecular Biochemicals, Germany) according to the instructions of the manufacturer, as described by Tayman [49]. Briefly, slices were rehydrated in a series of xylene and ethanol 
solutions and then incubated in a humidified chamber at room temperature for $20 \mathrm{~min}$ with proteinase K. Slices were then rinsed with tris-buffered saline (TBS). The entire specimens were covered with $3 \% \mathrm{H}_{2} \mathrm{O}_{2}$ and then incubated at room temperature for $5 \mathrm{~min}$. Slices were rinsed with TBS. TUNEL enzyme and label solution were mixed and applied to slices, which were incubated again in the humidified chamber for $1 \mathrm{~h}$ at $37^{\circ} \mathrm{C}$. Slices were thoroughly rinsed with TBS. Stop buffer, block buffer, and conjugate were applied in turn. Diaminobenzidine solution was applied for 10-15min to stain the nuclei of apoptotic cells. The hematoxylin was used to counter-stain the nuclei of normal cells. Slices were dehydrated in a series of three ethanol baths and twice xylene baths, $5 \mathrm{~min}$ for each. The nuclei of apoptotic cells were with green fluorescence (stained with FITC fluorescein-dUTP), or brown (stained with diaminobenzidine). The TUNEL positive cells (apoptotic cells) were counted using a computersupported imaging system connected to a light microscope (OlympusAX70) with an objective magnification of $\times 400$. Then apoptotic cells were quantified by Image-Pro Plus 5.1 (USA) image analysis software. Five sections in each group and five fields in each section were measured and averaged.

\section{Detection of mitochondrial membrane potential $(\Delta \psi \mathrm{m})$}

JC-1 (Cat.No.551302, BD, USA) was used to determine mitochondrial membrane potential $\left(\Delta \psi_{m}\right)$. A total of $1 \mathrm{~mL}$ cell suspension (made in procedure Annexin V-FITC/PI double staining assay) was transferred into $5 \mathrm{~mL}$ culture tube and centrifuged. Afterwards, $0.5 \mathrm{ml}$ of JC-1 working solution was immediately added and gently mixed. And then the mixture was incubated for 15 min at $37{ }^{\circ} \mathrm{C}$ under $5 \% \mathrm{CO}_{2}$ incubator. At the end of the incubation, cells were washed twice with $1 \times$ Assay Buffer cells, and then re-suspended in $450 \mu \mathrm{L} 1 \times$ Assay Buffer. And then $\Delta \psi \mathrm{m}$ was assayed by FCM within 30 minutes.

\section{Quantitative real-time PCR (qRT-PCR)}

At 7, 14, and 21 days of age, bursas of Fabricius from six birds in each group were removed and immediately stored in liquid nitrogen. Then, bursas of Fabricius were homogenized by crushing with a mortar and pestle. The powdered tissues were collected into eppendorf tubes and stored at $-80^{\circ} \mathrm{C}$. Total RNA was extracted from BF using TriPure Isolation Reagent (Cat No. 11667165001, Roche Applied Science, Germany) following the procedure provided by manufacturer. The yield of extraction was assessed by measuring light absorbency at $260 \mathrm{~nm}$, and the quality of RNA was detected by calculating the ratio of the absorbency at 260 and $280 \mathrm{~nm}$. Extracted RNA immediately reverse-transcribed into cDNA by using
Transcriptor First Strand cDNA Synthesis Kit (Cat No: 04897030001, Roche Applied Science, Germany), according to the manufacturer's instructions. And then the cDNA was used as a template for quantitative real-time PCR analysis.

For qRT-PCR reactions, $20 \mu \mathrm{L}$ mixtures were made by using FastStart Universal SYBR Green Master mix (Cat No: 04913914001, Roche Applied Science, Germany) containing $10 \mu \mathrm{L}$ faststart universal SYBR green master ( $\mathrm{ROX}), 0.6 \mu \mathrm{L}$ forward primer, $0.6 \mu \mathrm{L}$ reverse primer, $6.8 \mu \mathrm{L}$ RNAase-free water and $2 \mu \mathrm{L}$ cDNA. Reaction conditions were set to $10 \mathrm{~min}$ at $95{ }^{\circ} \mathrm{C}$ (first segment, one cycle), $10 \mathrm{~s}$ at $95^{\circ} \mathrm{C}$ and $30 \mathrm{~s}$ at melting temperature $\left(\mathrm{T}_{\mathrm{m}}\right)$ of a specific primer pair (second segment, 44 cycles) followed by $10 \mathrm{~s}$ at $95{ }^{\circ} \mathrm{C}$, and $72{ }^{\circ} \mathrm{C}$ for $10 \mathrm{~s}$ (dissociation curve segment) using Thermal Cycler (Step One Plus, Applied BioSystems, USA). Gene expression was analyzed, and $\beta$-actin was used as an internal control $[50,51]$. Sequence of primers was obtained from GenBank of NCBI. Primers were designed with Primer 5 and synthesized by Sangon Biotech (Shanghai, China) (Table 1). The qRT-PCR data were analyzed with $2^{-\Delta \Delta C t}$ calculation method described by Livak and Schmittgen [52].

\section{Biochemical analysis}

At 7, 14 and 21 days of age, six broilers in each group were euthanized and immediately necropsied. Then bursas of Fabricius were immediately removed and put into $0{ }^{\circ} \mathrm{C} 0.85 \% \mathrm{NaCl}$ solution. One gram bursa of Fabricius was homogenized with $9 \mathrm{~mL} 0.85 \% \mathrm{NaCl}$ solution. After the homogenates were centrifuged at $3500 \times \mathrm{g}$ at $4^{\circ} \mathrm{C}$, the total protein in the supernatant was determined by total protein quantification kit (A045-2). The activities of SOD (A001-1), CAT (A007), GSHPx (A005) and GR (A062), contents of GSH (A006) and MDA (A003-2), and total ant-oxidative capacity (T-AOC) (A015) in the supernatant were detected using commercial kits (NJJCBIO, Nanjing, China), according to the manufacturer's instructions.

\section{Statistical analysis}

The significance of difference between two groups was analyzed by variance analysis, and results are expressed as the mean value with deviation. The analysis was performed using the independent sample $t$ test of SPSS software for Mac v.20.0 (IBM Corp, Armonk, NY, USA) and a value of $p<0.05$ was considered significant, while $p$ value $<0.01$ was considered markedly significant.

\section{CONFLICTS OF INTEREST}

The authors declare no conflicts of interest. 
Table 2: A list of oligonucleotides used as primers in qRT-PCR analysis of gene expression in chicken bursa of Fabricius cells

\begin{tabular}{|c|c|c|c|c|}
\hline $\begin{array}{l}\text { Gene } \\
\text { symbol }\end{array}$ & $\begin{array}{c}\text { RefSeq } \\
\text { mRNAnumber }\end{array}$ & Forward primers & Reverse primers & $\begin{array}{l}\text { Amplicon } \\
\text { length (bp) }\end{array}$ \\
\hline GSH-Px & NM001277853 & TTGTAAACATCAGGGGCAAA & TGGGCCAAGATCTTTCTGTAA & 140 \\
\hline $\mathrm{CuZn-SOD}$ & NM205064 & CGCAGGTGCTCACTTTAATCC & CTATTTCTACTTCTGCCACTCCTCC & 119 \\
\hline Mn-SOD & NM204211 & CACTCTTCCTGACCTGCCTTACG & TTGCCAGCGCCTCTTTGTATT & 146 \\
\hline GR & GQ853055 & CTGTGGCAAAGCCCTCCTGA & ATGGGTGGGTGGCTGAAGAC & 135 \\
\hline CAT & NM001031215 & CTGTTGCTGGAGAATCTGGGTC & TGGCTATGGATGAAGGATGGAA & 160 \\
\hline Bcl-2 & NM_205339 & TGTTTCTCAAACCAGACACCAA & CAGTAGGCACCTGTGAGATCG & 205 \\
\hline Bcl-xl & NM_001025304 & GAGGTACCGGAGGGCTTTCA & CAAAGCTCTGGTACGCCGTG & 74 \\
\hline Bak-1 & NM_001030920 & CTGTTCGCTTCCTTCCCCTG & TTGCAGAGATGCTGTGGGAC & 167 \\
\hline Bax & XM_422067 & GGTGACAGGGATCGTCACAG & TAGGCCAGGAACAGGGTGAA & 108 \\
\hline Cyt c & K02303.1 & AGGCAAGCACAAGACTGGA & CTGACTATCACCAAGAACCACC & 150 \\
\hline Apaf-1 & XM_416167 & ACCTTTCCCGTCTGGTTGTTC & AGCAATCTCTCTCCGCTTTCT & 139 \\
\hline Casp-9 & AY057940 & CCAACCTGAGAGTGAGCGATT & GTACACCAGTCTGTGGGTCGG & 87 \\
\hline AIF & NM_001007490 & CTGGGTCCTGATGTGGGCTAT & TGTCCCTGACTGCTCTGTTGC & 123 \\
\hline Casp-3 & NM_204725 & TGGCCCTCTTGAACTGAAAG & TCCACTGTCTGCTTCAATACC & 139 \\
\hline Fas & NM_001199487 & TCCACCTGCTCCTCGTCATT & GTGCAGTGTGTGTGGGAACT & 78 \\
\hline FasL & NM_001031559 & GGCATTCAGTACCGTGACCA & CCGGAAGAGCACATTGGAGT & 78 \\
\hline FADD & XM_421073 & GGGGTAAAGAGGCTGAACTCTTA & TGAGTCCTATTGCACTGCTGTC & 163 \\
\hline Casp-8 & NM_204592 & GTCTCCGTTCAGGTATCTGCT & TCTCAATGAAAACGTCCGGC & 143 \\
\hline Casp-10 & XM_421936 & CTGGGGGCTCCAAAAGTCC & AAAGGGGGACAAAGCCAACA & 204 \\
\hline Bid & NM_204552 & GAGCAGCTTGCTGGAGAGAA & GAGGCAGCTGGATCACAAGT & 187 \\
\hline Grp78 & NM_205491 & GGTGTTGCTTGATGTGTGTCC & GCTGATTGTCAGAAGCTGTGG & 134 \\
\hline Grp94 & NM_204289 & TGACCTGGATGCAAAGGTGGA & TTAAACCCCACACCATCCCТCAAC & 250 \\
\hline $\mathrm{CaM}$ & NM_205005 & GGAGTTGGTAAAATGAGGGAACA & ACATTGTGGACGATTGACAGTCT & 233 \\
\hline p53 & NM_205264.1 & ACCTGCACTTACTCCCCGGT & TCTTATAGACGGCCACGGCG & 127 \\
\hline Akt1 & NM_205055.1 & AGGCAGCCTCCTCСТCTC & GGCTCCTCCTCCССТTCTC & 114 \\
\hline$\beta$-actin & L08165 & TGCTGTGTTCCCATCTATCG & TTGGTGACAATACCGTGTTCA & 178 \\
\hline
\end{tabular}

\section{REFERENCES}

1. Nogueira JA, Ono-Nita SK, Nita ME, de Souza MM, do Carmo EP, Mello ES, Scapulatempo C, ParanaguáVezozzo DC, Carrilho FJ, Alves VA. 249 TP53 mutation has high prevalence and is correlated with larger and poorly differentiated HCC in Brazilian patients. BMC Cancer. 2009; 9:204.

2. Seo JA, Yu JH. Toxigenic fungi and mycotoxins. Mycology. 2004; 22:689-721.

3. Eaton DL, Gallagher EP. Mechanisms of aflatoxin carcinogenesis. Annu Rev Pharmacol Toxicol. 1994; 34:135-172.
4. Diekman MA, Green ML. Mycotoxins and reproduction in domestic livestock. J Anim Sci. 1992; 70:1615-1627.

5. Keyl AC, Booth AN. Aflatoxin effects in livestock. J Am Oil Chem Soc. 1971; 48:599-604.

6. Eaton DL, Groopman JD. (2013). The toxicology of aflatoxins: human health, veterinary, and agricultural significance: Elsevier.

7. Ledoux DL, Rottinghaus GE, Bermudez AJ, Alonso-Debolt M. Efficacy of a hydrated sodium calcium aluminosilicate to ameliorate the toxic effects of aflatoxin in broiler chicks. Poult Sci. 1999; 78:204-210.

8. Yarru LP, Settivari RS, Gowda NKS, Antoniou E, Ledoux DR, Rottinghaus GE. Effects of turmeric (Curcuma 
longa) on the expression of hepatic genes associated with biotransformation, antioxidant, and immune systems in broiler chicks fed aflatoxin. Poult Sci. 2009; 88:2620-2627.

9. Andretta I, Kipper M, Lehnen CR, Hauschild L, Vale M, Lovatto P. Meta-analytical study of productive and nutritional interactions of mycotoxins in broilers. Poult Sci. 2011; 90:1934-1940.

10. Grenier B, Applegate TJ. Modulation of intestinal functions following mycotoxin ingestion: Meta-analysis of published experiments in animals. Toxins (Basel). 2013; 5:396-430.

11. Bintvihok A, Thiengnin S, Doi K, Kumagai S. Residues of aflatoxins in the liver, muscle and eggs of domestic fowls. J Vet Med Sci. 2002; 64:1037-1039.

12. Hussain Z, Khan MZ, Khan A, Javed I, Saleemi MK, Mahmood S, Asi MR. Residues of aflatoxin $\mathrm{B}_{1}$ in broiler meat: Effect of age and dietary aflatoxin $\mathrm{B}_{1}$ levels. Food Chem Toxicol. 2010; 48:3304-3307.

13. Bintvihok A, Davitiyananda D. Aflatoxins and their metabolites residues in chicken tissues from 5 parts $(10$ provinces) of Thailand. J Health Res. 2002; 16:37-54.

14. Yunus AW, Razzazi-Fazeli E, Bohm J. Aflatoxin B1 in affecting broiler's performance, immunity, and gastrointestinal tract: A review of history and contemporary issues. Toxins (Basel). 2011; 3:566-590.

15. Rawal S, Kim JE, Coulombe R. Aflatoxin B 1 in poultry: toxicology, metabolism and prevention. Res Vet Sci. 2010; 89:325-331.

16. He Y, Fang J, Peng X, Cui HM, Zuo ZC, Deng JL, Chen ZL, Lai WM, Shu G, Tang L. Effects of sodium selenite on aflatoxin $\mathrm{B}_{1}$-induced decrease of ileac $\mathrm{T}$ cell and the mRNA contents of IL-2, IL-6, and TNF- $\alpha$ in broilers. Biol Trace Elem Res. 2014; 159:167-173.

17. Chen KJ, Yuan SB, Chen J, Peng X, Wang FY, Cui HM, Fang J. Effects of sodium selenite on the decreased percentage of $\mathrm{T}$ cell subsets, contents of serum IL-2 and IFN- $\gamma$ induced by aflatoxin $\mathrm{B}_{1}$ in broilers. Res Vet Sci. 2013; 95:143-145.

18. Sirajudeen M, Gopi K, Tyagi JS, Moudgal RP, Mohan J, Singh R. Protective effects of melatonin in reduction of oxidative damage and immunosuppression induced by aflatoxin $\mathrm{B}_{1}$-contaminated diets in young chicks. Environ Toxicol. 2011; 26:153-160.

19. Guo S, Shi D, Liao S, Su R, Lin Y, Pan J, Tang Z. Influence of selenium on body weights and immune organ indexes in ducklings intoxicated with aflatoxin $\mathrm{B}_{1}$. Biol Trace Elem Res. 2012; 146:167-170.

20. Peng X, Bai S, Ding X, Zeng Q, Zhang K, Fang J. Pathological changes in the immune organs of broiler chickens fed on corn naturally contaminated with aflatoxins B1 and B2. Avian Pathol. 2015; 44:192-199.

21. Peng X, Zhang K, Bai S, Ding X, Zeng Q, Yang J, Fang J, Chen K. Histological lesions, cell cycle arrest, apoptosis and $\mathrm{T}$ cell subsets changes of spleen in chicken fed aflatoxin-contaminated corn. Int J Env Res Public Health. 2014; 11:8567-8580.

22. Chen J, Chen K, Yuan S, Peng X, Fang J, Wang F, Cui H, Chen Z, Yuan J, Geng Y. Effects of aflatoxin $B_{1}$ on oxidative stress markers and apoptosis of spleens in broilers. Toxicol Ind Health. 2016; 32: 278-284.

23. Manafi M, Murthy H, Swamy HN. Evaluation of different mycotoxin binders on aflatoxicosis in broiler breeders induced with aflatoxin B: effects on biochemical and immunological parameters. Am-Euras. J Agric \& Environ Sci. 2012; 12:429-433.

24. Green DR, Reed JC. Mitochondria and apoptosis. Science. 1998; 281:1309-1312.

25. Chen K, Shu G, Peng X, Fang J, Cui H, Chen J, Wang F, Chen Z, Zuo Z, Deng J. Protective role of sodium selenite on histopathological lesions, decreased T-cell subsets and increased apoptosis of thymus in broilers intoxicated with aflatoxin $B_{1}$. Food Chem Toxicol. 2013; 59:446-454.

26. Peng X, Chen K, Chen J, Fang J, Cui H, Zuo Z, Deng J, Chen Z, Geng Y, Lai W. Aflatoxin $\mathrm{B}_{1}$ affects apoptosis and expression of Bax, Bcl-2, and Caspase-3 in thymus and bursa of fabricius in broiler chickens. Environ Toxicol. 2015; doi: 10.1002/tox.22120.

27. Wang H, Liu H, Zheng ZM, Zhang KB, Wang TP, Sribastav SS, Liu WS, Liu T. Role of death receptor, mitochondrial and endoplasmic reticulum pathways in different stages of degenerative human lumbar disc. Apoptosis. 2011; 16:990-1003.

28. Peng X, Yu Z, Liang N, Chi X, Li X, Jiang M, Fang J, Cui H, Lai W, Zhou Y. The mitochondrial and death receptor pathways involved in the thymocytes apoptosis induced by aflatoxin $\mathrm{B}_{1}$. Oncotarget. 2016; 7:12222-12234. doi: 10.18632/oncotarget.7731.

29. Chen K, Fang J, Peng X, Cui H, Chen J, Wang F, Chen Z, Zuo Z, Deng J, Lai W. Effect of selenium supplementation on aflatoxin $\mathrm{B}_{1}$-induced histopathological lesions and apoptosis in bursa of Fabricius in broilers. Food Chem Toxicol. 2014; 74:91-97.

30. Ortatatli M, Oğuz H. Ameliorative effects of dietary clinoptilolite on pathological changes in broiler chickens during aflatoxicosis. Res Vet Sci. 2001; 71:59-66.

31. Kumar PA, Ana MSA, Vijayasarathi S, Gowda RS, Rao S. Pathology of lymphoid organs in aflatoxicosis and ochratoxicosis and immunomodulatory effect of vitamin $\mathrm{E}$ and selenium in broiler chicken. Indian J Vet Pathol. 2003; 27:102-106.

32. Peng X, Zhang S, Fang J, Cui H, Zuo Z, Deng J. Protective roles of sodium selenite against aflatoxin $B_{1}$-induced apoptosis of jejunum in broilers. Int J Env Res Public Health. 2014; 11:13130-13143.

33. Mary VS, Theumer MG, Arias SL, Rubinstein HR. Reactive oxygen species sources and biomolecular oxidative damage induced by aflatoxin $\mathrm{B}_{1}$ and fumonisin $\mathrm{B}_{1}$ in rat spleen mononuclear cells. Toxicology. 2012; 302:299-307. 
34. Hinton DM, Myers MJ, Raybourne RA, Francke-Carroll S, Sotomayor RE, Shaddock J, Warbritton A, Chou MW. Immunotoxicity of aflatoxin $B_{1}$ in rats: effects on lymphocytes and the inflammatory response in a chronic intermittent dosing study. Toxicol Sci. 2003; 73:362-377.

35. Ly JD, Grubb DR, Lawen A. The mitochondrial membrane potential $(\Delta \psi \mathrm{m})$ in apoptosis; an update. Apoptosis. 2003; 8:115-128.

36. Korsmeyer SJ. BCL-2 gene family and the regulation of programmed cell death. Cancer Res. 1999; 59:1693s-1700s.

37. Hu Q, Wu D, Chen W, Yan Z, Yan C, He T, Liang Q, Shi Y. Molecular determinants of caspase- 9 activation by the Apaf-1 apoptosome. P Natl A Sci. 2014; 111:16254-16261.

38. Szegezdi E, Logue SE, Gorman AM, Samali A. Mediators of endoplasmic reticulum stress-induced apoptosis. EMBO reports. 2006; 7:880-885.

39. Feng B, Yao PM, Li Y, Devlin CM, Zhang D, Harding HP, Sweeney M, Rong JX, Kuriakose G, Fisher EA. The endoplasmic reticulum is the site of cholesterolinduced cytotoxicity in macrophages. Nat Cell Biol. 2003; 5:781-792.

40. Gaut JR, Hendershot LM. The modification and assembly of proteins in the endoplasmic reticulum. Curr Opin Cell Biol. 1993; 5:589-595.

41. Han F. Single-prolonged stress induces endoplasmic reticulum-dependent apoptosis in the hippocampus in a rat model of post-traumatic stress disorder. PLoS One. 2013; 8:61-61.

42. Melnick J, Dul JL, Argon Y. Sequential interaction of the chaperones BiP and GRP94 with immunoglobulin chains in the endoplasmic reticulum. Nature. 1994; 370:373-375.

43. Morishima N, Nakanishi K, Takenouchi H, Shibata T, Yasuhiko Y. An endoplasmic reticulum stress-specific caspase cascade in apoptosis cytochrome c-independent activation of caspase- 9 by caspase-12. J Biol Chem. 2002; 277:34287-34294.
44. Marin DE, Taranu I. Overview on aflatoxins and oxidative stress. Toxin Rev. 2012; 31:32-43.

45. Theumer MG, Cánepa MC, López AG, Mary VS, Dambolena JS, Rubinstein HR. Subchronic mycotoxicoses in Wistar rats: Assessment of the in vivo and in vitro genotoxicity induced by fumonisins and aflatoxin $\mathrm{B}_{1}$, and oxidative stress biomarkers status. Toxicology. 2010; 268:104-110.

46. Jorgenson TC, Zhong W, Oberley TD. Redox imbalance and biochemical changes in cancer. Cancer Res. 2013; 73:6118-6123.

47. Council NR. (1994). National research council nutrient requirements of poultry: ninth revised edition. (Washington, DC, USA: National Academies Press).

48. Kaoud HA. Innovative methods for the amelioration of aflatoxin $\left(\mathrm{AFB}_{1}\right)$ effect in broiler chicks. Sci J Appl Res. 2013; 1:15-19.

49. Tayman C, Tonbul A, Kosus A, Hirfanoglu IM, Haltas H, Uysal S, Tatli MM, Andiran F. Protective effects of caffeic acid phenethyl ester (CAPE) on intestinal damage in necrotizing enterocolitis. Pediatr Surg Int. 2011; 27:1179-1189.

50. Hong YH, Lillehoj HS, Lillehoj EP, Lee SH. Changes in immune-related gene expression and intestinal lymphocyte subpopulations following Eimeria maxima infection of chickens. Vet Immunol Immunopathol. 2006; 114:259-272.

51. Shini S, Kaiser P. Effects of stress, mimicked by administration of corticosterone in drinking water, on the expression of chicken cytokine and chemokine genes in lymphocytes. Stress. 2009; 12:388-399.

52. Livak KJ, Schmittgen TD. Analysis of relative gene expression data using real-time quantitative PCR and the 2- $\Delta \Delta$ CT method. Methods. 2001; 25:402-408. 